\title{
Time trends in HPV vaccination according to country background: a nationwide register-based study among girls in Norway
}

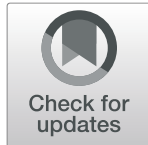

Randi Dalene Bjerke ${ }^{1}$, Ida Laake $2^{2^{*}}$, Berit Feiring ${ }^{2}$, Geir Aamodt ${ }^{1}$ and Lill Trogstad ${ }^{2}$

\begin{abstract}
Background: Since the human papillomavirus (HPV) vaccine was introduced in Norway in 2009, the vaccine uptake has increased. Whether this increase is similar regardless of the girls' country background is unknown. We examined changes in HPV vaccine uptake from 2009 to 2014 and studied the impact of parental education and income on HPV vaccine uptake according to country background.

Methods: Girls in the first six birth cohorts (1997-2002) eligible for HPV vaccination were identified through the National Registry. Information on HPV vaccination, country background and socioeconomic factors was extracted from the Norwegian Immunisation Registry and Statistics Norway. Risk differences (RDs) and confidence intervals (Cls) were estimated with linear binomial regression. A total of 177,387 girls were included in the study.

Results: The HPV vaccine uptake increased from $72.5 \%$ in 2009 to $87.3 \%$ in 2014. The uptake increased for girls in all country background categories. Highest vaccine uptake was observed in girls with East-/South-East Asian background, $88.9 \%$ versus $82.5 \%$ in the total population. Vaccine uptake decreased slightly with increasing parental education, $\mathrm{RD}=-1.6 \%$ (95\% Cl: $-2.3 \%$ to $-0.8 \%)$ for highest compared with lowest education level. In contrast, the uptake increased with increasing household income, $\mathrm{RD}=4.9 \%(95 \% \mathrm{Cl}, 4.3$ to 5.5\%) for highest compared with lowest quintile. Parental education had largest impact in girls with Asian background, RD $=-8.1 \%(95 \% \mathrm{Cl}-10.5 \%$ to $-5.6 \%)$ for higher vs lower education. The largest impact of household income was observed in girls with background from Middle East/Africa, RD for a 200,000 NOK increase in income was 2.1\% (95\% Cl 1.2 to 3.0\%).

Conclusions: The HPV vaccine uptake differed with country background but increased over time in all country background categories. Moreover, the impact of education and income on vaccine uptake differed with country background.
\end{abstract}

Keywords: Human papillomavirus, Childhood immunisation programme, HPV vaccine, Immigrant background, Socioeconomic factors, Parental education, Income, Time trends

\footnotetext{
* Correspondence: ida.laake@fhi.no

${ }^{2}$ Division of Infection Control and Environmental Health, Norwegian Institute of Public Health, Oslo, Norway

Full list of author information is available at the end of the article
}

(C) The Author(s). 2021 Open Access This article is licensed under a Creative Commons Attribution 4.0 International License, which permits use, sharing, adaptation, distribution and reproduction in any medium or format, as long as you give appropriate credit to the original author(s) and the source, provide a link to the Creative Commons licence, and indicate if changes were made. The images or other third party material in this article are included in the article's Creative Commons licence, unless indicated otherwise in a credit line to the material. If material is not included in the article's Creative Commons licence and your intended use is not permitted by statutory regulation or exceeds the permitted use, you will need to obtain permission directly from the copyright holder. To view a copy of this licence, visit http://creativecommons.org/licenses/by/4.0/ The Creative Commons Public Domain Dedication waiver (http://creativecommons.org/publicdomain/zero/1.0/) applies to the data made available in this article, unless otherwise stated in a credit line to the data. 


\section{Background}

Infection with human papillomavirus (HPV) is the most common sexually transmitted infection. HPV-infection is a necessary cause of cervical cancer. In addition, there is evidence linking HPV-infection with cancers of the anus, vulva, vagina, penis, and oropharynx [1]. Since 2009, HPV vaccine has been offered free of charge to all Norwegian 12-years-old girls through a school-based programme within the Norwegian Childhood Immunisation Programme (NCIP) [2]. The quadrivalent vaccine, Gardasil $^{\circledR}$, was used from the introduction in autumn 2009. After a new tender, the bivalent vaccine Cervarix ${ }^{\oplus}$ has been used since autumn 2017. The HPV vaccination coverage is steadily increasing, but is still lower than for the other childhood vaccines offered through the NCIP. As of 2019, the vaccination coverage among 16-yearolds (born in 2003) is $89 \%$ for HPV vaccine (girls only), and $94 \%$ for the other vaccines [3].

In a previous study, we reported socioeconomic differences in HPV vaccine uptake among girls in Norway [4]. The proportion of girls initiating HPV vaccination increased with increasing maternal income. In contrast, high maternal education was associated with lower likelihood of initiating HPV vaccination. A Canadian study with data from a publicly funded school-based programme reported similar findings on education [5]. Moreover, differences in initiation of HPV vaccination according to country background have been reported in other countries with publicly funded immunisation programmes [6-9].

Since the HPV vaccine was introduced in the NCIP, the coverage has increased [3]. However, it is not known if the increase is similar regardless of the girls' country background. Moreover, whether education and income can be of different importance depending on country background has not been assessed. The aim of the present study was to investigate changes over time in HPV vaccine uptake in Norway according to country background. Moreover, we examined whether the impact of parental education and income on HPV vaccine uptake differed with country background.

\section{Materials and methods}

\section{Study design and data sources}

The study is based on national registries. Information on dates of birth, immigration, emigration, and death was obtained from the National Registry. Information on HPV vaccination was obtained from the Norwegian Immunisation Registry. Information on maternal and paternal education level, household income in 2011, country of birth of the study participants and their parents, number of siblings, and county of residence was extracted from Statistics Norway. Data from the different registries were linked using the unique identification number assigned to all residents of Norway. The current study was approved by The Norwegian Regional Committee for Medical and Health Research Ethics, "Ref 2012/ 1619/REK Sør-Øst”.

\section{Study population}

Girls in the first six birth cohorts eligible for HPV vaccination through the NCIP (born 1997-2002) were identified through the National Registry, $n=189,828$ (Fig. 1). Since we were only interested in girls who were offered the HPV vaccine, we excluded 9320 girls not residing in Norway on September 1, the year they turned 12, i.e. at the start of 7th grade when the vaccine was offered. Furthermore, we excluded girls with missing information on both maternal and paternal education, household income, maternal age, and region of residence, leaving 177,387 girls eligible for analysis.

\section{Outcome variable}

All girls were offered three doses of HPV vaccine. The outcome variable 'HPV vaccine uptake' was defined as receipt of at least one dose of the HPV vaccine, as of June 19, 2015.

\section{Exposure variables}

The main exposure was 'Programme year'. Each programme year corresponds to an academic year running from 20 August to 20 June the following year [4]. During each programme year (2009-2014), the vaccine was offered to only one birth cohort. Thus, year of birth was used to allocate programme year. In the main analysis, programme year was treated as a categorical variable with the first year as the reference category.

'Country background' was defined as "Norwegian" if at least one parent was born in Norway. Otherwise, country background was defined as the girl's country of birth if she was foreign born, or as her mother's country of birth if she was born in Norway. Country background was categorised as: 'Norway', 'Western Europe', 'Centraland Eastern Europe (including previous Soviet republics)', 'Middle East and North Africa', 'South-Asia', 'East -/South-East Asia', 'Sub-Saharan Africa', and 'America and Oceania' (see Supplementary table) for countries in each category). In some analyses, the original eight categories were combined into the following four categories; 'Norway', 'Europe, America, and Oceania', 'Middle East and Africa', and 'Asia'. The categorisation was based on the countries' epidemiological similarity and geographic closeness.

'Parental education' was defined as maternal education level. If information on maternal education was missing, paternal education was used. Parental education was categorised into four categories: 'Primary/ lower secondary school' ( $\leq 10$ years of schooling); 'Upper secondary 


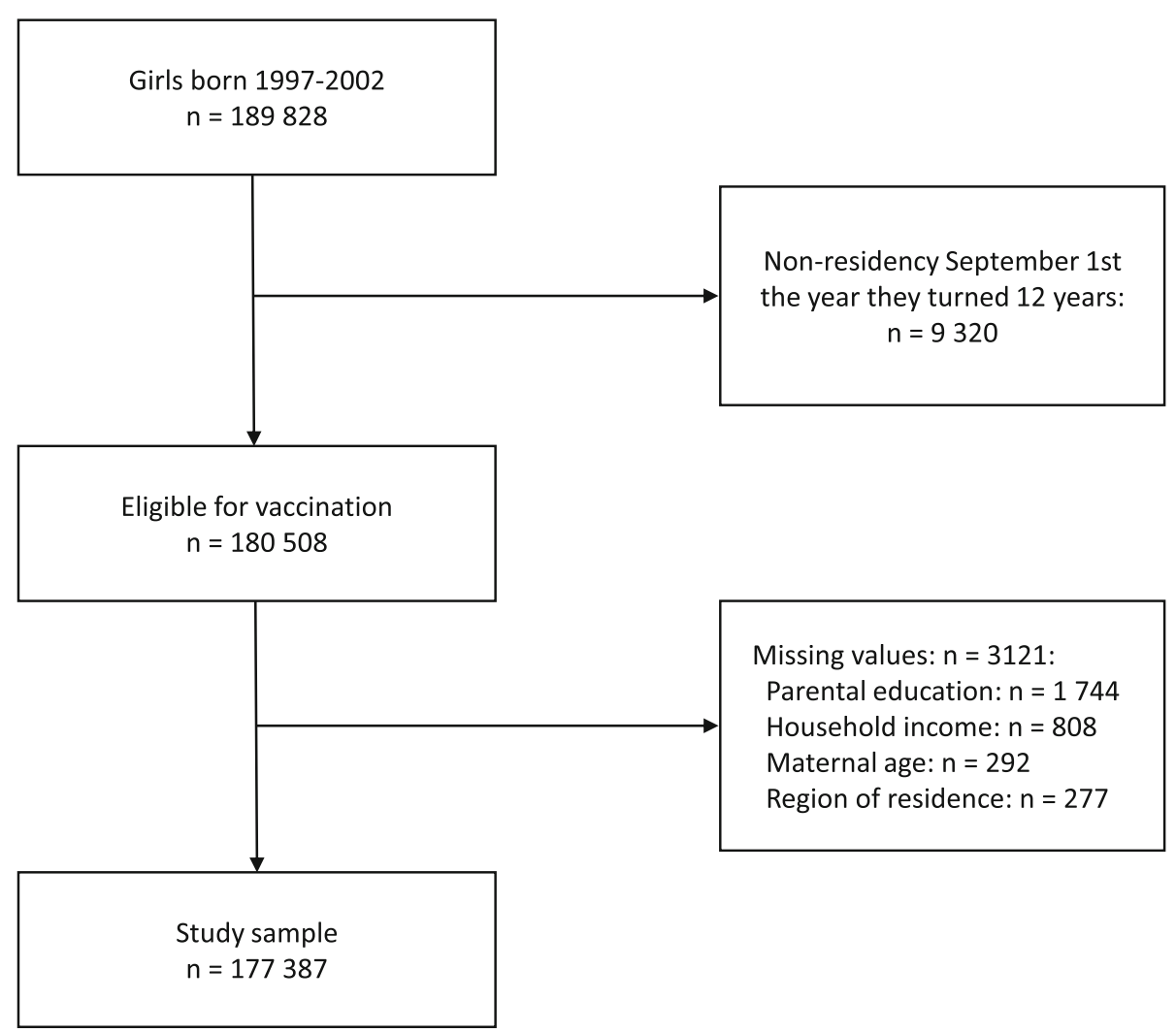

Fig. 1 Flow chart of study population

school' (11-14 years of schooling); 'Higher education, undergraduate level' (14-17 years of schooling); and 'Higher education, graduate level' ( $\geq 18$ years of schooling). We also used a two-category version of 'Parental education' with the categories lower education $(\leq 14$ years) and higher education ( $>14$ years).

'Household income', the household total gross income, was divided into quintiles. For all birth cohorts, we used household income from 2011. This was the most recent information on household income that was available in our data. Thus, for the youngest birth cohorts, we did not have information on household income from the year before vaccination. Moreover, the proportion of girls with missing household income was substantially lower for 2011 than for household income from the previous years, due to possible non-residency prior to 2011.

\section{Covariates}

'Number of siblings' was categorised as $0,1,2,3$, and $\geq 4$. 'Maternal age at time of daughter's birth' was categorised into age categories $\leq 25,26-30,31-35$, and $>35$ years. 'Region of residence' was defined as Oslo, Eastern-Norway, Southern-Norway, Western-Norway, Mid-Norway, and Northern-Norway.

\section{Statistical analysis}

We modelled the association between the main exposures (programme year/year of birth, country background, parental education, and household income) and the outcome variable (initiation of HPV vaccination), using linear binomial regression to estimate risk differences (RDs) and corresponding 95\% confidence intervals (CIs). The multivariable model also included number of siblings, maternal age at daughter's birth, and region of residence. These factors were considered potential confounders since they are associated with HPV vaccine uptake and with parental education and household income. The difference in earnings by educational level is smaller in Norway than in other high-income countries [10]. This is reflected in the weak correlation between parental education and household income observed in our data (Spearman's rank correlation coefficient $=0.34$ ). Thus, we were not concerned about collinearity between parental education and household income.

Changes in vaccine uptake over time by country background (with four categories) was examined by including interaction terms between programme year (continuous) and country background. Programme year was treated as a continuous variable in this analysis in order to limit the number of parameters in the model. The impact of 
parental education and household income by country background was assessed by including interaction terms between country background and parental education (higher compared to lower), and between country background and household income (continuous). In these analyses, we used a Poisson model with robust standard deviation to estimate RDs because the linear binomial model failed to converge [11]. In these models, RDs for each category of country background was calculated as the sum of the coefficient corresponding to the main effect and the coefficient corresponding to the appropriate interaction term.

All tests were two-sided, and $p<0.05$ was considered statistically significant. Statistical analyses were performed using STATA/SE 15.0 (StataCorp. College Station, Texas USA).

\section{Results}

\section{Characteristics of the study population}

Of the 177,387 girls included in the study, the majority had Norway as country background (89.5\%) (Table 1). The percentage of girls in each of the other country background categories was 1-2\%. Upper secondary school (11-14 years) was the most common parental education level (37.6\%), while $8.4 \%$ had parents with the highest education level ( $\geq 18$ years of schooling). Median household income level was 901,243 NOK (IQR 656,053 NOK-1,268,988 NOK).

\section{Uptake of HPV vaccine}

A total of $146,403(82.5 \%)$ girls initiated HPV vaccination (Table 1). Initiation of HPV vaccination increased from $72.5 \%$ among girls in the first programme year (born in 1997), to $87.3 \%$ among girls in the sixth programme year (born in 2002) (Table 2). In total, the HPV vaccine uptake was $82.6 \%$ among girls with Norwegian background and $81.6 \%$ among girls with nonNorwegian background. Overall, girls from East-/SouthEast Asia had the highest HPV vaccine uptake (88.9\%).

The uptake in girls with South-Asian, and East -/South-East Asian background was significantly higher than in girls with Norwegian background, multivariable RDs were $4.9 \%$ (95\% CI: 3.8 to $5.9 \%$ ) and $5.4 \%$ (95\% CI: 4.3 to $6.6 \%$ ), respectively (Table 2). Girls with background from Western-Europe, Central- and EasternEurope, Sub-Saharan Africa, and America and Oceania were significantly less likely to initiate HPV vaccination, as compared to girls with Norwegian background, multivariable RDs were -7.9 (95\% CI: -9.7 to -6.1 ), -3.3 (95\% CI: -4.6 to -2.1$),-3.4$ (95\% CI: -5.0 to -1.8 ), and -5.5 ( $95 \%$ CI: -8.8 to -2.2 ), respectively.

Initiation of HPV vaccination decreased slightly with increasing parental education. Compared to girls with parents in the category primary school/compulsory, girls with parents in the categories 'higher education, undergraduate level' and 'higher education, graduate level' were significantly less likely to initiate HPV vaccination, with multivariable RDs $-0.8 \%$ (95\% CI: $-1.4 \%$ to $0.3 \%$ ) and $-1.6 \%$ (95\% CI: $-2.3 \%$ to $-0.8 \%$ ), respectively (Table 2). In contrast, we found a positive association between household income and initiation of HPV vaccination. Compared to girls in household income quintile 1, girls in household income quintiles $2,3,4$, and 5 were significantly more likely to initiate HPV vaccination, RDs were $1.4 \%$ (95\% CI: 0.9 to $2.0 \%$ ), $3.7 \%$ (95\% CI: 3.1 to $4.2 \%$ ), $4.2 \%$ (95\% CI: 3.7 to $4.8 \%$ ), and $4.9 \%$ (95\% CI: 4.3 to $5.5 \%$ ), respectively.

\section{Changes over time (2009-2014) in HPV vaccine uptake by country background}

Figure 2 shows the HPV vaccine uptake by programme year and country background. In all country background categories, the uptake increased from 2009 to 2014. Initially, girls with Norwegian background had a lower HPV vaccine uptake than girls with background from Central- and Eastern Europe, Middle East and North Africa, South-Asia, and East- and South-East Asia.

There was an overall significant interaction between programme year and country background $(p<0.001)$. The increase in HPV vaccine uptake was significantly higher for girls with Norwegian background than for girls with other country backgrounds (all $p<0.001$ ), the multivariable RD corresponding to increase in HPV vaccine uptake per year was $2.7 \%$ (95\% CI: 2.6 to $2.8 \%$ ) for Norway, $1.0 \%$ (95\% CI: 0.4 to 1.6\%) for Europe/America/ Oceania, $1.3 \%$ (95\% CI: 0.7 to $1.8 \%$ ) for Middle East/Africa, and 1.6\% (95\% CI: 1.2 to $2.1 \%$ ) for Asia (Table 3).

\section{Impact of higher parental education by country background}

Girls with Norwegian background were more likely to have parents with higher education (46.0\%) than girls with background from Europe, America, and Oceania (39.3\%), Middle East and Africa (17.2\%), and Asia (19.5\%) (Table 4). We found a significant interaction between parental education and country background $(p<0.001)$. Higher parental education was significantly associated with lower vaccine uptake among girls in all country background categories. However, the association was weak among girls with Norwegian background, RD was $-0.6 \%$ (95\% CI: $-1.0 \%$ to $-0.2 \%)$. The association was stronger for girls with country background Asia or Europe/America/Oceania, RDs were $-8.1 \%$ (95\% CI: $-10.5 \%$ to $-5.6 \%$ ) and $-7.8 \%$ (95\% CI: $-9.9 \%$ to $-5.6 \%$ ), respectively. For girls with Middle Eastern and African background the RD was $-2.7 \%$ ( $95 \% \mathrm{CI}$ : 5.3 to -0.02 ). 
Table 1 Characteristics of the study population. Girls offered HPV vaccine during 2009-2014 $(n=177,387)$

\begin{tabular}{ll}
\hline & n (\%) \\
\hline HPV vaccine uptake & \\
Initiated & $146,403(82.5)$ \\
Did not initiate & $30,984(17.5)$ \\
Country background ${ }^{\mathbf{a}}$ & \\
Norway & $158,738(89.5)$ \\
Western Europe & $2072(1.2)$ \\
Central- and Eastern Europe & $3887(2.2)$ \\
Middle East and North Africa & $3729(2.1)$ \\
South-Asia & $3355(1.9)$ \\
East-/South-East Asia & $2236(1.3)$ \\
Sub-Saharan Africa & $2775(1.6)$ \\
America and Oceania & $595(0.3)$
\end{tabular}

Year of birth (Programme year)

1997 (2009)

1998 (2010)

1999 (2011)

2000 (2012)

$2001(2013)$

2002 (2014)

Parental education (years of schooling)

Primary school/compulsory level $(\leq 10)$

Upper secondary level (11-14)

Higher education, undergraduate level (14-17)

Higher education, graduate level $(\geq 18)$

Household income quintile (NOK)

$$
\begin{aligned}
& 1(\leq 575,319) \\
& 2(575,320-811,300) \\
& 3(811,301-988,227) \\
& 4(988,228-1,251,798) \\
& 5(\geq 1,251,799)
\end{aligned}
$$

Number of siblings

0
1
2
3
$\geq 4$

Maternal age at time of daughter's birth (years)

$$
\begin{aligned}
& \leq 25 \\
& 26-30 \\
& 31-35 \\
& >35
\end{aligned}
$$

Region of residence

$34,736(19.6)$

$35,412(20.0)$

$35,704(20.1)$

$35,778(20.2)$

$35,757(20.2)$

8203 (4.6)

$66,237(37.3)$

$62,468(35.2)$

24,561 (13.9)

$38,939(22.0)$

$64,254(36.2)$

$22,247(12.5)$
Table 1 Characteristics of the study population. Girls offered HPV vaccine during 2009-2014 ( $n=177,387)$ (Continued)

\begin{tabular}{ll}
\hline & $\mathbf{n}(\%)$ \\
\hline Eastern-Norway & $45,259(25.5)$ \\
Southern-Norway & $34,892(20.1)$ \\
Western-Norway & $39,283(22.2)$ \\
Mid-Norway & $24,948(14.1)$ \\
Northern-Norway & $17,116(9.7)$ \\
\hline
\end{tabular}

HPV Human papillomavirus

atist of countries in each category is provided in the Supplementary table

${ }^{b}$ Each programme year, the vaccine was offered to only one birth cohort

\section{Impact of higher household income, by country} background

Median household income (in NOK) was 930,136 for girls with Norwegian background, 685,123 for girls with European, American, and Oceanian background, 534,160 for girls with Middle Eastern and African background, and 698,839 for girls with Asian background (Table 5). We found a significant interaction between household income and country background $(p<0.001)$. There was a significant association between household income and initiation of HPV vaccination among girls with Norway and Middle East/Africa as country background. However, the association was weak among girls with Norwegian background, the RD for a 200,000 NOK increase in income was $0.2 \%$ (95\% CI: 0.1 to $0.4 \%$ ). The association was stronger for girls with Middle East/Africa as country background, $\mathrm{RD}=2.1 \%$ (95\% CI: 1.2 to $3.0 \%)$. Household income was not significantly associated with initiation of HPV vaccination for girls with Asia or Europe/America/Oceania as country background.

$15,918(9.0)$

$51,947(29.3)$

\section{Discussion}

In this nationwide registry-based study, we studied the impact of country background, parental education, and household income on initiation of HPV vaccination in 12-year-old Norwegian girls between 2009 and 2014. We found an increase in HPV vaccine uptake over time among all girls regardless of country background. While girls with Asian background had the highest total HPV vaccine uptake, girls with Norwegian background had the highest increase in HPV vaccine uptake per year. Higher parental education was negatively associated with HPV vaccine uptake in all country background categories, but the association was weak for girls with Norwegian background. In contrast, higher household income was positively associated with HPV vaccine uptake. However, this was only significant among girls with Norwegian and Middle East/African backgrounds.

We found an increase in initiation of HPV vaccination over time among all categories of country background. 15,889 (9.0) Girls with Norwegian background started with a lower HPV vaccine uptake than several of the other country 
Table 2 HPV vaccination uptake among girls offered HPV vaccine during 2009-2014 $(n=177,387)$

\begin{tabular}{|c|c|c|c|c|c|}
\hline & \multirow{2}{*}{$\begin{array}{l}\text { HPV vaccine } \\
\text { uptake }^{\mathrm{a}} \\
\mathrm{n}(\%)\end{array}$} & \multicolumn{2}{|l|}{ Univariable model $^{\mathbf{b}}$} & \multicolumn{2}{|c|}{ Multivariable model $^{b, c}$} \\
\hline & & $\mathrm{RD}(95 \% \mathrm{CI})$ & $P$-value & $\mathrm{RD}(95 \% \mathrm{Cl})$ & $P$-value \\
\hline \multicolumn{6}{|l|}{ Country background $^{d}$} \\
\hline Norway & $131,185(82.6)$ & 0 (Ref) & & 0 (Ref) & \\
\hline Western Europe & $1544(74.5)$ & $-8.1(-10.1$ to -6.2$)$ & $<0.001$ & $-7.9(-9.7$ to -6.1$)$ & $<0.001$ \\
\hline Central- and Eastern Europe & $3098(79.7)$ & $-2.9(-4.2$ to -1.7$)$ & $<0.001$ & $-3.3(-4.6$ to -2.1$)$ & $<0.001$ \\
\hline Middle East and North Africa & $3079(82.6)$ & $-0.1(-1.3$ to 1.2$)$ & 0.91 & $0.8(-0.4$ to 2.0$)$ & 0.20 \\
\hline South-Asia & $2925(87.2)$ & 4.5 (3.4 to 5.7$)$ & $<0.001$ & 4.9 (3.8 to 5.9$)$ & $<0.001$ \\
\hline East-/South-East Asia & $1987(88.9)$ & $6.2(4.9$ to 7.5$)$ & $<0.001$ & $5.4(4.3$ to 6.6$)$ & $<0.001$ \\
\hline Sub-Saharan Africa & $2130(76.8)$ & $-5.9(-7.4$ to -4.3$)$ & $<0.001$ & $-3.4(-5.0$ to -1.8$)$ & $<0.001$ \\
\hline America and Oceania & $455(76.5)$ & $-6.2(-9.5$ to -2.7$)$ & $<0.001$ & $-5.5(-8.8$ to -2.2$)$ & 0.001 \\
\hline \multicolumn{6}{|l|}{ Year of birth (Programme year) } \\
\hline 1997 (2009) & $21,896(72.5)$ & 0 (Ref) & & 0 (Ref) & \\
\hline $1998(2010)$ & $24,086(81.1)$ & 8.5 (7.9 to 9.2$)$ & $<0.001$ & 8.6 (8.0 to 9.3$)$ & $<0.001$ \\
\hline $1999(2011)$ & $25,136(83.5)$ & $11.0(10.4$ to 11.7$)$ & $<0.001$ & $11.2(10.5$ to 11.8$)$ & $<0.001$ \\
\hline $2000(2012)$ & $25,463(84.6)$ & $12.1(11.5$ to 12.8$)$ & $<0.001$ & $12.4(11.7$ to 13.0$)$ & $<0.001$ \\
\hline 2001 (2013) & $25,104(86.8)$ & $14.3(13.7$ to 14.9$)$ & $<0.001$ & $14.4(13.8$ to 15.1$)$ & $<0.001$ \\
\hline $2002(2014)$ & $24,718(87.3)$ & $14.8(14.1$ to 15.4$)$ & $<0.001$ & $15.1(14.5$ to 15.7$)$ & $<0.001$ \\
\hline \multicolumn{6}{|l|}{ Parental education (years of schooling) } \\
\hline Primary school/compulsory level & $26,946(82.0)$ & 0 (Ref) & & 0 (Ref) & \\
\hline Upper secondary level & $55,157(82.7)$ & $0.7(0.2$ to 1.2$)$ & 0.007 & $-0.1(-0.6$ to 0.4$)$ & 0.64 \\
\hline Higher education, undergraduate level & $52,132(82.8)$ & $0.8(0.2$ to 1.3$)$ & 0.004 & $-0.8(-1.4$ to -0.3$)$ & 0.001 \\
\hline Higher education, graduate level & $12,168(82.2)$ & $0.2(-0.6$ to 0.9$)$ & 0.63 & $-1.6(-2.3$ to -0.8$)$ & $<0.001$ \\
\hline \multicolumn{6}{|l|}{ Household income quintile (NOK) } \\
\hline $1(\leq 575,319)$ & $27,687(79.7)$ & 0 (Ref) & & 0 (Ref) & \\
\hline $2(575320-811,300)$ & $28,874(81.5)$ & 1.8 (1.2 to 2.4$)$ & $<0.001$ & 1.4 (0.9 to 2.0) & $<0.001$ \\
\hline $3(811301-988,227)$ & $29,888(83.7)$ & $4.0(3.4$ to 4.5$)$ & $<0.001$ & 3.7 (3.1 to 4.2 ) & $<0.001$ \\
\hline $4(988228-1,251,798)$ & 29,972 (83.8) & 4.1 (3.5 to 4.6 ) & $<0.001$ & 4.2 (3.7 to 4.8$)$ & $<0.001$ \\
\hline $5(\geq 1,251,799)$ & 29,982 (83.9) & 4.1 (3.5 to 4.7 ) & $<0.001$ & 4.9 (4.3 to 5.5$)$ & $<0.001$ \\
\hline \multicolumn{6}{|l|}{ Number of siblings } \\
\hline 0 & $6558(80.0)$ & 0 (Ref) & & 0 (Ref) & \\
\hline 1 & $55,421(83.7)$ & 3.7 (2.8 to 4.6$)$ & $<0.001$ & 2.9 (2.0 to 3.8$)$ & $<0.001$ \\
\hline 2 & $52,142(83.5)$ & 3.5 (2.6 to 4.4$)$ & $<0.001$ & 2.5 (1.7 to 3.4$)$ & $<0.001$ \\
\hline 3 & $19,825(80.7)$ & $0.8(-0.2$ to 1.8$)$ & 0.13 & $0.4(-0.5$ to 1.4$)$ & 0.37 \\
\hline$\geq 4$ & $12,457(78.3)$ & $-1.7(-2.8$ to -0.6$)$ & 0.002 & $-1.2(-2.3$ to -0.2$)$ & 0.02 \\
\hline \multicolumn{6}{|c|}{ Maternal age at time of daughter's birth (years) } \\
\hline$\leq 25$ & $32,515(83.5)$ & 0 (Ref) & & 0 (Ref) & \\
\hline $26-30$ & $53,690(83.6)$ & $0.1(-0.4$ to 0.5$)$ & 0.81 & $-0.8(-1.3$ to -0.4$)$ & $<0.001$ \\
\hline $31-35$ & $42,760(82.3)$ & $-1.2(-1.7$ to -0.7$)$ & $<0.001$ & $-2.3(-2.8$ to -1.8$)$ & $<0.001$ \\
\hline$>35$ & $17,438(78.4)$ & $-5.1(-5.8$ to -4.5$)$ & $<0.001$ & $-5.4(-6.1$ to -4.8$)$ & $<0.001$ \\
\hline \multicolumn{6}{|l|}{ Region of residence } \\
\hline Oslo & $12,968(81.6)$ & 0 (Ref) & & 0 (Ref) & \\
\hline Eastern-Norway & $37,721(83.3)$ & 1.7 (1.0 to 2.4$)$ & $<0.001$ & $1.1(0.4$ to 1.8$)$ & 0.001 \\
\hline Southern-Norway & $28,671(82.2)$ & $0.6(-0.2$ to 1.3$)$ & 0.13 & $0.1(-0.6$ to 0.9$)$ & 0.69 \\
\hline Western-Norway & $32,551(82.9)$ & $1.2(0.5$ to 2.0$)$ & 0.001 & $0.4(-0.3$ to 1.1$)$ & 0.28 \\
\hline
\end{tabular}


Table 2 HPV vaccination uptake among girls offered HPV vaccine during 2009-2014 ( $n=177,387)$ (Continued)

\begin{tabular}{|c|c|c|c|c|c|}
\hline & \multirow{2}{*}{$\begin{array}{l}\text { HPV vaccine } \\
\text { uptake }^{\mathrm{a}} \\
\mathrm{n}(\%)\end{array}$} & \multicolumn{2}{|c|}{ Univariable model $^{\mathbf{b}}$} & \multicolumn{2}{|c|}{ Multivariable model $^{\mathrm{b}, \mathrm{c}}$} \\
\hline & & $\mathrm{RD}(95 \% \mathrm{Cl})$ & $P$-value & $\mathrm{RD}(95 \% \mathrm{Cl})$ & $P$-value \\
\hline Mid-Norway & $20,321(81.5)$ & $-0.2(-0.9$ to 0.6$)$ & 0.68 & $-0.6(-1.3$ to 0.2 & 0.15 \\
\hline Northern-Norway & $14,171(82.8)$ & 1.2 (0.4 to 2.0$)$ & 0.005 & $0.7(-0.1$ to 1.5$)$ & 0.09 \\
\hline
\end{tabular}

$H P V$ human papillomavirus, $R D$ risk difference, $\mathrm{Cl}$ confidence interval

${ }^{a}$ Receipt of at least one dose of HPV vaccine

${ }^{\mathrm{b}}$ Risk differences are estimated with linear binomial regression

' The model included country background, year of birth, parental education level, household income, number of siblings, maternal age at time of daughter's birth, and region of residence

${ }^{d}$ List of countries in each category is provided in the Supplementary table

e Each programme year, the vaccine was offered to only one birth cohort

background categories. However, girls with Norwegian background had the highest increase per year. Possible explanations for this might be increased information and more positive attitudes towards the HPV vaccine. Increased information and positive focus on the vaccine may have had a more positive effect on Norwegian parents leading to greater willingness to accept vaccination compared to immigrant parents. Preceding the introduction of the HPV vaccine, Norwegian parents may have been more influenced by the heavy, negative discussions in the media and therefore more reluctant to vaccinate their daughters during the first programme years [1214]. This would be in line with recent findings in a Danish study [15] that found that the decline in uptake following the public debate on the safety of the HPV vaccine in Denmark was less pronounced in immigrants and descendants of immigrants compared to native Danes, and suggested that these groups may be less influenced by the negative public debate than native Danes. Another Danish study examined the relation between a lower HPV vaccine uptake and increased media coverage in Denmark, mainly regarding suspected adverse events, such as POTS, following HPV vaccination [16]. Findings from the study indicate that this may have contributed to a lower HPV vaccine uptake among girls eligible for vaccination between 2013 and 2016 in Denmark. However, these claims do not appear to have affected the HPV uptake in Norway to a large extent.

Previous studies have reported a lower HPV vaccine uptake among girls with immigrant background $[6,7$, 9 , 15, 17]. A Scottish cross-sectional study found the HPV vaccine uptake to be significantly lower for girls with Polish background, as compared to girls from the United Kingdom [18]. Studies conducted in Denmark and Sweden, with publicly funded HPV vaccine programmes, reported a lower proportion of girls initiating HPV vaccination among girls with immigrant background [6-9].

In the present study, girls with country background from Western Europe and Central-/Eastern Europe had a lower likelihood of initiating HPV vaccination, as compared to girls with Norwegian background. This is in line with previous findings from Denmark [8]. The lower

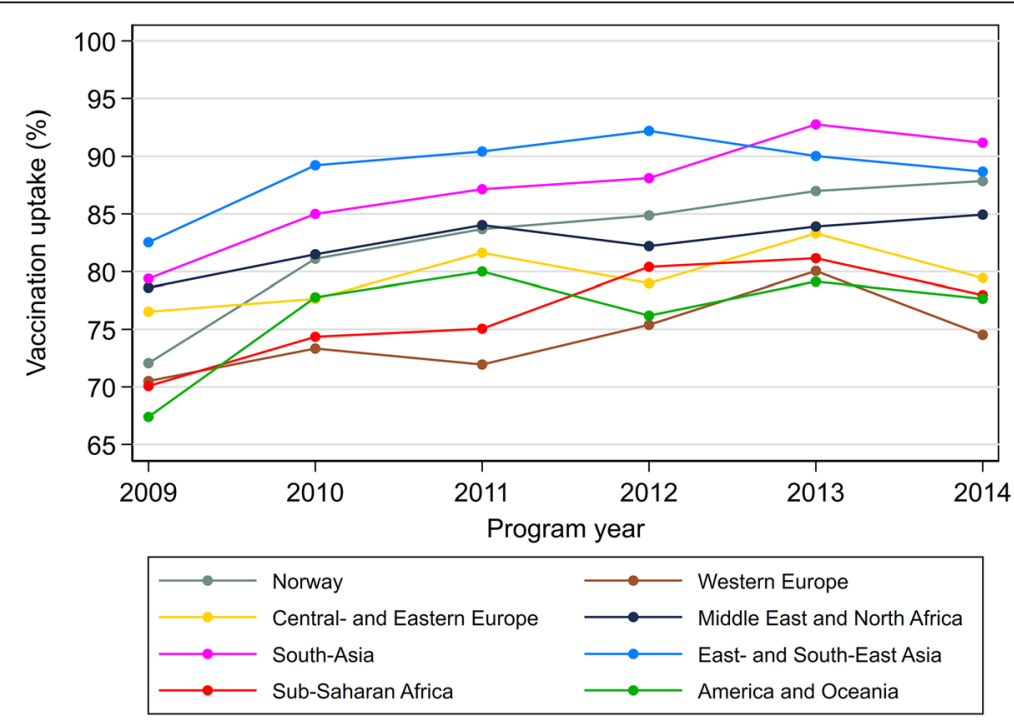

Fig. 2 Uptake of at least one dose of HPV vaccine according to country of origin 
Table 3 Increase in HPV vaccine uptake per year (2009-2014) according to country background

\begin{tabular}{|c|c|c|c|c|}
\hline & \multicolumn{2}{|c|}{ HPV vaccine uptake ${ }^{a}$} & \multicolumn{2}{|c|}{ Multivariable model $^{\mathbf{b}}$} \\
\hline & $\begin{array}{l}2009 \\
\text { n (\%) }\end{array}$ & $\begin{array}{l}2014 \\
\text { n (\%) }\end{array}$ & $\mathrm{RD}(95 \% \mathrm{Cl})$ & $P$-value \\
\hline \multicolumn{5}{|l|}{ Country background ${ }^{c}$} \\
\hline Norway & $19,706(72.1)$ & $22,023(87.9)$ & 2.7 (2.6 to 2.8$)$ & $<0.001$ \\
\hline Europe, America, and Oceania & $684(73.7)$ & $936(77.8)$ & $1.0(0.4$ to 1.6$)$ & 0.001 \\
\hline Middle East and Africa & $755(75.2)$ & $954(81.8)$ & 1.3 (0.7 to 1.8$)$ & $<0.001$ \\
\hline Asia & $751(80.7)$ & $805(90.2)$ & $1.6(1.2$ to 2.1$)$ & $<0.001$ \\
\hline
\end{tabular}

HPV Human papillomavirus, $R D$ Risk difference, $\mathrm{Cl}$ Confidence interval

${ }^{\text {a }}$ Receipt of at least one dose of HPV vaccine

${ }^{b}$ Risk differences are estimated with linear binomial regression. The model included country background, year of birth (corresponding to programme year), parental education level, household income, number of siblings, maternal age at time of daughter's birth, region of residence, and interaction terms between country background and year of birth. RDs correspond to the change in HPV vaccine uptake per year

'List of countries in each category is provided in the Supplementary table

uptake among these girls reflects the uptake in their countries of origin [19].

We observed that girls from Sub-Saharan Africa, America, and Oceania, were less likely to initiate HPV vaccination, as compared to Norwegian girls. Lower initiation of HPV vaccination among ethnic minorities has been related to integration and language barriers as well as cultural norms and religious beliefs [17, 20]. Information about the HPV vaccine in several languages (Arabic, English, French, Northern Sami, Polish, Russian, Somali, Spanish, Tigrinya, and Urdu) is available on the Norwegian Institute of Health's website and for school health nurses to use when informing parents prior to vaccination [2, 21]. A Canadian systematic review found that cultural norms, knowledge gaps, and anti-vaccination beliefs were barriers to vaccinations [22]. These factors might be possible explanations for the lower HPV vaccine uptake among girls from Sub-Saharan Africa, America, and Oceania. However, our data do not include information on parental attitudes or beliefs.

The highest probability of initiating HPV vaccination was found among girls with country backgrounds from Asia. To our knowledge, a higher uptake among Asian girls, compared to non-immigrants, has not been observed in other countries than Norway and Denmark $[15,23]$. The nationwide Danish study by Hertzum et al. [15], found that daughters of immigrants from Mid- and Eastern Asia had a higher HPV vaccine uptake as compared to daughters of native Danes ( $87 \%$ vs. $85 \%)$. Possible explanations for the findings in our study might be that Asian parents residing in Norway generally have positive attitudes towards the HPV vaccine, and that they consider it a privilege that the vaccine is offered free of charge. In our study, the majority of girls in the category East-/South-East Asia had Vietnam as country background (42\%). In Vietnam, the HPV vaccine has not yet been included in the immunisation programme [24]. However, the vaccination coverage for other vaccines offered through the Vietnamese immunisation programme is high, and has increased from 2000 to 2015 [25, 26]. Hence, a high vaccination coverage in Vietnam might have positively affected attitudes among Vietnamese parents' residing in Norway.

Despite a weak association, we found that the likelihood of initiating HPV vaccination decreased with increasing parental education level, which is similar to a

Table 4 Impact of parental education on HPV vaccine uptake according to country background

\begin{tabular}{|c|c|c|c|c|c|}
\hline & \multirow{2}{*}{$\begin{array}{l}\text { Higher } \\
\text { education } \\
\mathrm{n}(\%)\end{array}$} & \multicolumn{2}{|c|}{ HPV vaccine uptake ${ }^{a}$} & \multicolumn{2}{|l|}{ Multivariable model $^{\mathbf{b}}$} \\
\hline & & $\begin{array}{l}\text { Lower } \\
\text { education } \\
\mathrm{n}(\%)\end{array}$ & $\begin{array}{l}\text { Higher } \\
\text { education } \\
\mathrm{n}(\%)\end{array}$ & $\mathrm{RD}(95 \% \mathrm{Cl})^{\mathrm{b}}$ & $P$-value \\
\hline \multicolumn{6}{|l|}{ Country background $^{c}$} \\
\hline Norway & $73,023(46.0)$ & $70,561(82.3)$ & $60,624(83.0)$ & $-0.6(-1.0$ to -0.2$)$ & 0.005 \\
\hline Europe, America, and Oceania & $2576(39.3)$ & 3199 (80.4) & $1898(73.7)$ & $-7.8(-9.9$ to -5.6$)$ & $<0.001$ \\
\hline Middle East and Africa & $1121(17.2)$ & $4328(80.4)$ & $881(78.6)$ & $-2.7(-5.3$ to -0.02$)$ & 0.048 \\
\hline Asia & $1091(19.5)$ & $4015(89.2)$ & $897(82.2)$ & $-8.1(-10.5$ to -5.6$)$ & $<0.001$ \\
\hline
\end{tabular}

HPV Human papillomavirus, $R D$ Risk difference, $\mathrm{Cl}$ Confidence interval

${ }^{a}$ Receipt of at least one dose of HPV vaccine

${ }^{b}$ Risk differences are estimated with linear binomial regression. The model included country background, year of birth, parental education level, household income, number of siblings, maternal age at time of daughter's birth, region of residence, and interaction terms between country background and parental education level. RDs correspond to the difference in HPV vaccine uptake between girls with higher parental education and girls with lower parental education

${ }^{c}$ List of countries in each category is provided in the Supplementary table 
Table 5 Impact of household income on HPV vaccine uptake according to country background

\begin{tabular}{|c|c|c|c|}
\hline & \multirow{2}{*}{$\begin{array}{l}\text { Household income, } \\
\text { median (NOK) }\end{array}$} & \multicolumn{2}{|c|}{ Multivariable model $^{a}$} \\
\hline & & $\mathrm{RD}(95 \% \mathrm{Cl})$ & $P$-value \\
\hline \multicolumn{4}{|l|}{ Country background $^{b}$} \\
\hline Norway & 930,136 & 0.2 (0.1 to 0.4$)$ & $<0.001$ \\
\hline Europe, America, and Oceania & 685,123 & $-0.2(-0.6$ to 0.3$)$ & 0.44 \\
\hline Middle East and Africa & 534,160 & 2.1 (1.2 to 3.0$)$ & $<0.001$ \\
\hline Asia & 698,839 & $-0.4(-1.0$ to 0.2$)$ & 0.19 \\
\hline
\end{tabular}

Canadian study with data from a publicly funded schoolbased programme [5]. These findings are somewhat surprising, because it has been reported that highly educated people are more receptive to health information and use of health services, and make more active health related choices, as compared to people with lower education [27]. Both a Swedish and a Danish study reported an increased likelihood of initiation of HPV vaccination with increasing maternal education level $[6,7]$. In Norway, parents with higher education may be more cautious towards the HPV vaccine than parents with only compulsory schooling, but this could not be assessed in our study since we did not have information on parental attitudes.

The negative association between higher parental education level and initiation of HPV vaccination was observed among girls in all categories of country background. Moreover, the association was stronger among girls with non-Norwegian background, as compared to girls with Norwegian background. To our knowledge, this is the first study to evaluate potential differences according to country background of the impact of parental education on HPV vaccine uptake. The stronger association among girls with non-Norwegian background might be explained by larger variations in educational attainment among parents with different country backgrounds. The proportion with higher parental education was $46 \%$ for girls with Norwegian background, but only 13\% for girls with background from Sub-Saharan Africa. A reasonable explanation might be that a larger proportion of higher parental education leads to smaller differences in initiation of HPV vaccination.

In contrast to the negative association between higher parental education level and initiation of HPV vaccination, the proportion of girls initiating HPV vaccination increased with increasing household income. This is in line with two previous studies from low- and middleincome countries that reported that parental income was a barrier to achieving a sufficient childhood vaccination coverage [28, 29], as well as a Danish study, that reported that high maternal income was associated with higher probability of initiating HPV vaccination [6].

We also found significant interactions between household income and country background. The association was strongest for Middle East/Africa. A possible explanation might be related to differences in income between different categories of country background. Median household income was lowest for Middle East/Africa. A 200,000 NOK increase in income is a larger relative increase in categories with low income, and therefore the effect might be larger among these categories. To our knowledge, this is the first study to report that the impact of parental income in initiation of HPV vaccination differs with country background.

A major strength of this study is the large sample size and the diversity of the study participants. Our study includes individual data from different population-based registries, covering the total population. Hence, we were able to include girls from six birth cohorts eligible for HPV vaccination, as well as controlling for numerous confounders. A high proportion of girls were included in the study population (93.4\%), thereby limiting selection bias. Another strength of using national registries, is that our study does not rely on self-reported data, which contributes to high quality and less misclassifications of outcomes and exposures. Notification to the Norwegian Immunisation Registry is mandatory for all vaccinations provided within the childhood immunisation programme. Moreover, vaccinations received abroad are also notifiable to the immunisation registry [30]. Thus, the potential misclassification due to vaccination abroad before arrival in Norway is limited.

Still, the present study also has limitations. With such a large dataset, we might detect significant results for clinically insignificant differences. Thus, results should be interpreted with caution. In order to detect a difference of 3 percentage points between the lowest income quintile and any other quintile with $90 \%$ power, we would need only 3519 individuals in each income quintile ( $10 \%$ of the number of girls in our study), if we 
assume that the vaccine uptake is $80 \%$ in the lowest income quintile and that the association between income and vaccine uptake is positive. Moreover, we would need 112,193 girls with Norwegian background and 1571 girls with East-/South-East Asian background (71\% of the number of girls in our study) to detect a difference in vaccine uptake of 3 percentage points between these two groups with $90 \%$ power, if we assume that the vaccine uptake is $83 \%$ among girls with Norwegian background, that the ratio between the number of girls with Norwegian background and East/South-East Asian background is the same as in our study, and that the vaccine uptake is higher among girls with East-/South-East Asian background. For the last programme year (2014) there may be some delay in registration of vaccination in the immunisation registry [31] which may explain an apparent decline in the HPV uptake in 2014. Moreover, a larger proportion of girls with missing information on parents' education, as well as income, did not have Norway as country background. Also, the study only has income data from 2011, and we were not able to assess the significance of change in income over time. Despite a small difference, the $3121(1.7 \%)$ girls excluded due to missing information, were slightly less likely to initiate HPV vaccination, than girls in the final study population $(82.3 \%$ vs $82.5 \%)$. This could be a limitation, due to the small proportion of girls in other country categories than Norway.

\section{Conclusions}

In summary, the present study found inequalities in the uptake of the HPV vaccine related to both country background and socioeconomic factors in the publicly funded school-based programme in Norway.

Our findings are encouraging; girls in all country background categories experienced a higher HPV vaccine uptake in 2014 than in 2009. Nevertheless, the vaccine uptake still differs with country background. Our observations indicate that education and income are important predictors of disparities in HPV vaccine uptake. Moreover, these factors differ with country backgrounds.

\section{Abbreviations}

Cl: Confidence interval; HPV: Human papillomavirus; NCIP: Norwegian Childhood Immunisation ProgrammeRDRisk difference

\section{Supplementary Information}

The online version contains supplementary material available at https://doi. org/10.1186/s12889-021-10877-8.

Additional file 1: Supplementary table. Countries in each category of country background.

\section{Authors' contributions}

$R D B, B F, G A$, and $L T$ conceived of the study. BF and $L T$ was responsible for the data acquisition. RDB and IL performed the statistical analyses. RDB drafted the manuscript. All authors contributed to the interpretation of the data. All authors revised the manuscript critically for important intellectual content. All authors read and approved the final manuscript.

\section{Funding}

The National surveillance of HPV vaccination programme is funded by the Norwegian Institute of Public Health and the Norwegian Ministry of Health and Care Services.

\section{Availability of data and materials}

The data analyzed during this study consist of sensitive information on an individual level. Due to protection of privacy and restrictions from the Norwegian Data Inspectorate and the Regional Committee for Medical and Health Research Ethics, the data cannot be made publicly available.

\section{Declarations}

Ethics approval and consent to participate

The current study was approved by The Norwegian Regional Committee for Medical and Health Research Ethics (REC), "Ref 2012/1619/REK Sør-Øst". REC granted exemption from the requirement of consent from the individuals included in this register-based study.

Consent for publication

Not applicable.

\section{Competing interests}

The authors have no competing interests.

\section{Author details}

${ }^{1}$ Department of Public Health Science, Norwegian University of Life Sciences, Ås, Norway. ${ }^{2}$ Division of Infection Control and Environmental Health, Norwegian Institute of Public Health, Oslo, Norway.

Received: 29 October 2020 Accepted: 20 April 2021

Published online: 03 May 2021

References

1. Zur Hausen H. Papillomaviruses in the causation of human cancers - a brief historical account. Virology. 2009;384(2):260-5. https://doi.org/10.1016/j. virol.2008.11.046.

2. Norwegian Institute of Public Health. Vaccine against HPV (human papillomavirus). https://www.fhi.no/en/id/vaccines/childhood-immunisationprogramme/vaccines-in-CIP/vaccine-against-hpv-human-papilloma-virus/. Accessed 19 Mar 2021.

3. Norwegian Institute of Public Health. Statistikk for barnevaksinasjon. https:// www.fhi.no/hn/helseregistre-og-registre/sysvak/barnevaksinasjon\%2D\%2Dstatistikk/. Accessed 19 Mar 2021.

4. Feiring B, Laake I, Molden T, Cappelen I, Håberg SE, Magnus P, et al. Do parental education and income matter? A nationwide register-based study on HPV vaccine uptake in the school-based immunisation programme in Norway. BMJ Open. 2015;5(5):e006422. https://doi.org/10.1136/bmjopen-2 014-006422

5. Ogilvie G, Anderson M, Marra F, McNeil S, Pielak K, Dawar M, et al. A population-based evaluation of a publicly funded, school-based HPV vaccine program in British Columbia, Canada: parental factors associated with HPV vaccine receipt. PLoS Med. 2010;7(5):e1000270. https://doi.org/1 0.1371/journal.pmed.1000270.

6. Slattelid Schreiber SM, Juul KE, Dehlendorff C, Kjaer SK. Socioeconomic predictors of human papillomavirus vaccination among girls in the Danish childhood immunization program. J Adolesc Health. 2015;56(4):402-7. https://doi.org/10.1016/j.jadohealth.2014.12.008.

7. Wang J, Ploner A, Sparen P, Lepp T, Roth A, Arnheim-Dahlstrom L, et al. Mode of HPV vaccination delivery and equity in vaccine uptake: a nationwide cohort study. Prev Med. 2019;120:26-33. https://doi.org/10.1016/ j.ypmed.2018.12.014

8. Widgren K, Simonsen J, Valentiner-Branth P, Molbak K. Uptake of the human papillomavirus-vaccination within the free-of-charge childhood vaccination 
programme in Denmark. Vaccine. 2011;29(52):9663-7. https://doi.org/10.101 6/j.vaccine.2011.10.021.

9. Grandahl M, Larsson M, Dalianis T, Stenhammar C, Tyden T, Westerling R, et al. Catch-up HPV vaccination status of adolescents in relation to socioeconomic factors, individual beliefs and sexual behaviour. PLoS One. 2017;12(11):e0187193. https://doi.org/10.1371/journal.pone.0187193.

10. OECD. Education at a Glance 2020: OECD Indicators. Paris: OECD Publishing; 2020. https://doi.org/10.1787/69096873-en.

11. Zou G. A modified poisson regression approach to prospective studies with binary data. Am J Epidemiol. 2004;159(7):702-6. https://doi.org/10.1093/aje/ kwh090.

12. Haug C. Drømmevaksine eller fortsatt en drøm? [Dream vaccine or still a dream?]. Tidsskr Nor Laegeforen. 2007;127(10):1331 (In Norwegian).

13. Haug C. Fra undring til uro [from uncertainty to anxiety]. Tidsskr Nor Laegeforen. 2007;127(13):1763 (In Norwegian).

14. Haug CJ. Human papillomavirus vaccination--reasons for caution. N Engl J Med. 2008:359(8):861-2. https://doi.org/10.1056/NEJMe0804638.

15. Hertzum-Larsen R, Thomsen LT, Frederiksen K, Kjaer SK. Human papillomavirus vaccination in immigrants and descendants of immigrants in Denmark. Eur J Cancer Prev. 2020;29(2):149-56. https://doi.org/10.1097/CEJ. 0000000000000524.

16. Suppli $\mathrm{CH}$, Hansen ND, Rasmussen $M$, Valentiner-Branth $P$, Krause $T G$, Molbak K. Decline in HPV-vaccination uptake in Denmark - the association between HPV-related media coverage and HPV-vaccination. BMC Public Health. 2018;18(1):1360. https://doi.org/10.1186/s12889-0186268-x.

17. Bowyer HL, Forster AS, Marlow LA, Waller J. Predicting human papillomavirus vaccination behaviour among adolescent girls in England: results from a prospective survey. J Fam Plann Reprod Health Care. 2014; 40(1):14-22. https://doi.org/10.1136/jprhc-2013-100583.

18. Pollock KG, Tait B, Tait J, Bielecki K, Kirolos A, Willocks L, et al. Evidence of decreased HPV vaccine acceptance in polish communities within Scotland. Vaccine. 2019;37(5):690-2. https://doi.org/10.1016/j.vaccine.2018.10.097.

19. Bruni L, Saura-Lazaro A, Montoliu A, Brotons M, Alemany L, Diallo MS, et al. HPV vaccination introduction worldwide and WHO and UNICEF estimates of national HPV immunization coverage 2010-2019. Prev Med. 2021;144: 106399. https://doi.org/10.1016/j.ypmed.2020.106399.

20. Gerend MA, Zapata C, Reyes E. Predictors of human papillomavirus vaccination among daughters of low-income Latina mothers: the role of acculturation. J Adolesc Health. 2013;53(5):623-9. https://doi.org/10.1016/j.ja dohealth.2013.06.006.

21. Norwegian Institute of Public Health. Vaksine mot HPV (humant papillomavirus) oversatt til ni språk. https://www.fhi.no/publ/informasjonsa rk/vaksine-mot-hpv/. Accessed 19 Mar 2021.

22. Wilson L, Rubens-Augustson T, Murphy M, Jardine C, Crowcroft N, Hui C, et al. Barriers to immunization among newcomers: a systematic review. Vaccine. 2018;36(8):1055-62. https://doi.org/10.1016/j.vaccine.2018.01.025.

23. Hansen BT, Campbell S, Burger E, Nygard M. Correlates of HPV vaccine uptake in school-based routine vaccination of preadolescent girls in Norway: a register-based study of 90,000 girls and their parents. Prev Med. 2015;77:4-10. https://doi.org/10.1016/j.ypmed.2015.04.024.

24. Thi Nguyen DN, Simms K, Vu Nguyen $H Q$, Van Tran T, Nguyen NH, LaMontagne DS, et al. The burden of cervical cancer in Vietnam: synthesis of the evidence. Cancer Epidemiol. 2019;59:83-103. https://doi.org/10.1016/j. canep.2018.11.008.

25. Nguyen NT, Vu HM, Dao SD, Tran HT, Nguyen TXC. Digital immunization registry: evidence for the impact of mHealth on enhancing the immunization system and improving immunization coverage for children under one year old in Vietnam. Mhealth. 2017;3:26. https://doi.org/10.21037/ mhealth.2017.06.03.

26. Nguyen TD, Dang AD, Van Damme P, Nguyen CV, Duong HT, Goossens $\mathrm{H}$, et al. Coverage of the expanded program on immunization in Vietnam: results from 2 cluster surveys and routine reports. Hum Vaccin Immunother. 2015;11(6):1526-33. https://doi.org/10.1080/21645515.2015.1 032487.

27. Statistics Norway. Hva betyr utdanning for vår helseatferd? https://www.ssb. no/helse/artikler-og-publikasjoner/hva-betyr-utdanning-for-vaar-helseatferd. Accessed 19 Mar 2021

28. Mutua MK, Kimani-Murage E, Ettarh RR. Childhood vaccination in informal urban settlements in Nairobi, Kenya: who gets vaccinated? BMC Public Health. 2011;11(1):6. https://doi.org/10.1186/1471-2458-11-6.
29. Akmatov MK, Mikolajczyk RT. Timeliness of childhood vaccinations in 31 low and middle-income countries. J Epidemiol Community Health. 2012;66(7): e14. https://doi.org/10.1136/jech.2010.124651.

30. Lovdata. Forskrift om innsamling og behandling av helseopplysninger i Nasjonalt vaksinasjonsregister (SYSVAK-registerforskriften). https://lovdata.no/ dokument/SF/forskrift/2003-06-20-739. Accessed 22 Mar 2021.

31. Trogstad L, Ung G, Hagerup-Jenssen M, Cappelen I, Haugen IL, Feiring B. The Norwegian immunisation register--SYSVAK. Euro Surveill. 2012; 17(16):20147.

\section{Publisher's Note}

Springer Nature remains neutral with regard to jurisdictional claims in published maps and institutional affiliations.
Ready to submit your research? Choose BMC and benefit from:

- fast, convenient online submission

- thorough peer review by experienced researchers in your field

- rapid publication on acceptance

- support for research data, including large and complex data types

- gold Open Access which fosters wider collaboration and increased citations

- maximum visibility for your research: over $100 \mathrm{M}$ website views per year

At BMC, research is always in progress.

Learn more biomedcentral.com/submissions 